\title{
Examination of the effect of sensor properties on the secondary battery model in simulation environment
}

\author{
I. Lakatos ${ }^{1}$, P. Körös ${ }^{2}$, F. Hajdu ${ }^{3}$ \\ ${ }^{1}$ Széchenyi István University, Department of Automotive \\ and Railway Engineering \\ Egyetem tér 1., 9026 Győr, HUNGARY \\ E-mail: lakatos@sze.hu \\ ${ }^{2,3}$ Széchenyi István University, Department of Mechatronics and \\ Machine Designes \\ Egyetem tér 1., 9026 Győr, HUNGARY \\ E-mail: korosp@sze.hu, hajdfl@sze.hu
}

Abstract: The aim of the presented method is to develop a simulation environment which is able to handle diagnostic tools of electric vehicles. Steps of forming the simulation environment are described in the article. Implementation of real sensors is not dealt with. The structure of a modular and easily adaptable testing approach is explained.

Keywords: drivetrain, battery, simulation

\section{Introduction}

Numerous software vendors and research teams work on development of vehicle simulation programmes these days. There are several possibilities for us to use this kind of software at our university. During our research, AVL CRUISE is used for drivetrain simulation while IPG Carmaker is used for calculations in vehicle dynamics. Our own tested and inserted models were prepared in MATLAB and Simulink programming environment.

The vehicle modelled and presented below is the car developed and built in 2013 by SZENERGY Team of our University. (Fig. 1.) This car participated in the Shell Eco Marathon race. The reason why we chose this vehicle as the object of our research is the availability of simulation parameters even from its design phase. At the same time, the model can be validated with the help of the existing vehicle. Whereas the control unit built in the vehicle enables measurements of the data needed for validation. 


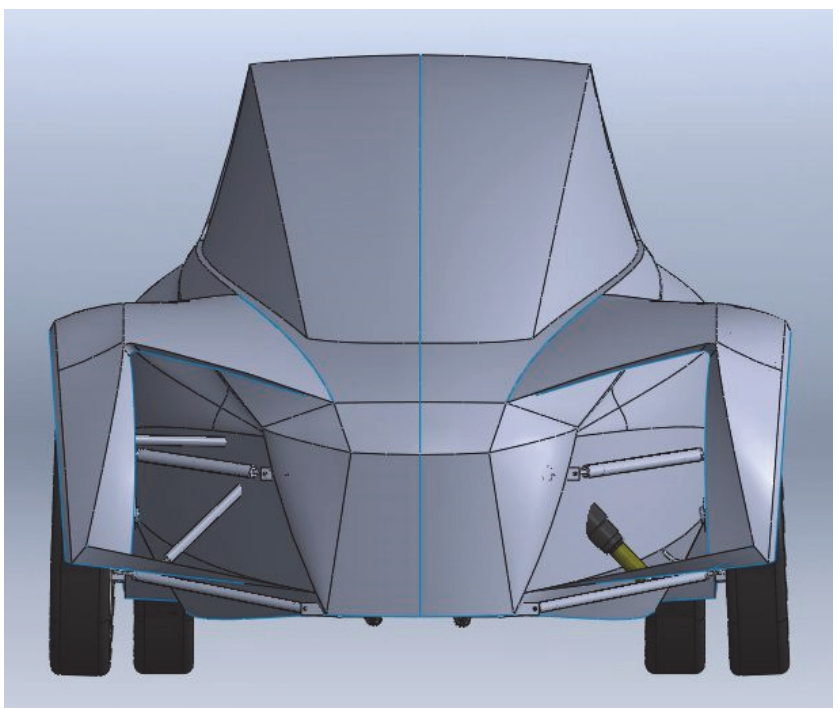

Figure 1. CAD model of the 2013 SZENERGY vehicle

\section{Elaboration of the Carmaker model}

As the first step, the Carmaker programme model was established based on the CAD models. The AVL Cruise simulation can be attached directly to the Carmaker model. Parameters that cannot be measured easily (like the drag coefficient for instance) were determined by means of a simulation program.

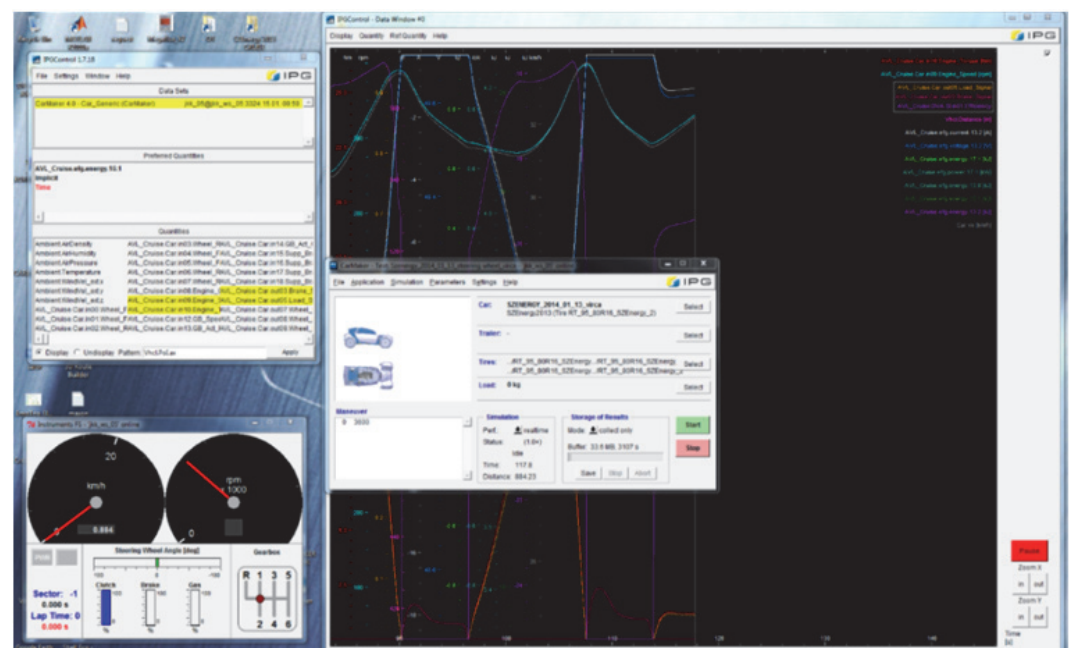

Figure 2. IPG Carmaker simulation program for vehicle dynamics 
Characteristics of the PMSM with the given controller were measured on test bench. This was used as a basis for building the drivetrain model.

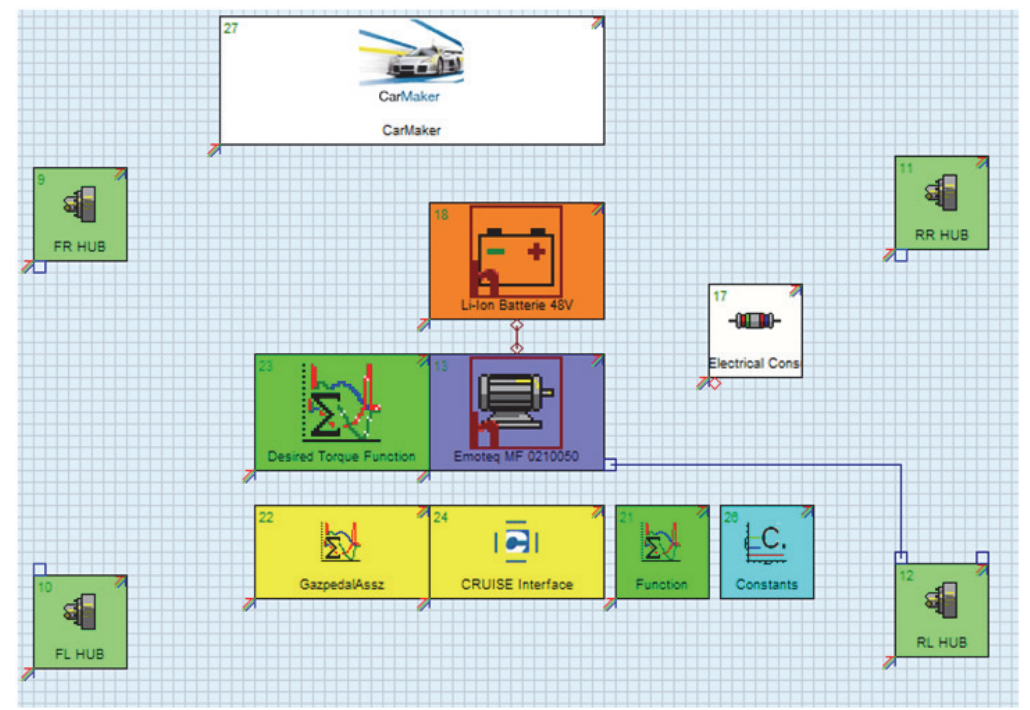

Figure 3. AVL CRUISE drivetrain model

The battery model to be tested was realised as a Simulink model.

\section{The battery model established}

The chosen model is built according to Chen and Rincón-Mora's [1], and Knauff's [2] method. In reference [3], the selection of the modelling principle and the properties of similar models are described in detail. The main characteristics of the model built by ourselves are the following:

- $\quad$ internal resistance and open circuit voltage (Uoc) are the function of the state of charge (SOC),

- the model is empirical, its parameters are determined by measurements,

- applicable to any battery, only the coefficient values change,

- heating effect, ageing and the number of cycles are not dealt with,

- input characteristics of the model: load current,

- output characteristics of the model: voltage, obtained energy, SOC, efficiency

- $\quad$ parameters: capacitance, number of series and parallel cells, maximum and minimum permissible voltage,

- voltage has to be between the given maximum and minimum values,

- $\quad$ in order to easier handling, the parameters were at first given with the help of a Matlab script which can be easily modified any time.

Differential equations (1) to (2) [2] which describe the operation of the model: 


$$
\begin{gathered}
\dot{\mathrm{x}}=\left[\begin{array}{ccc}
0 & 0 & 0 \\
0 & -\left(\mathrm{R}_{\mathrm{TS}} \mathrm{C}_{\mathrm{TS}}\right)^{-1} & 0 \\
0 & 0 & \left(\mathrm{R}_{\mathrm{TL}} \mathrm{C}_{\mathrm{TL}}\right)^{-1}
\end{array}\right] \mathrm{x}+\left[\begin{array}{c}
-\mathrm{C}_{\mathrm{CAP}}{ }^{-1} \\
-\mathrm{C}_{\mathrm{TS}}{ }^{-1} \\
-\mathrm{C}_{\mathrm{TL}}{ }^{-1}
\end{array}\right] \mathrm{i} \\
u=\mathrm{g}\left(\mathrm{x}_{1}\right)+\mathrm{x}_{2}+\mathrm{x}_{3}+\mathrm{R}_{\mathrm{s}} \mathrm{u}
\end{gathered}
$$

Within the equation, $R_{t s}, C_{t s}, R_{t l}$ and $C_{t l}$ are the capacitances and resistances of the transient RC circuits, $C_{c a p}$ is the total capacitance of the battery, $R_{s}$ stands for the internal resistance, $\mathrm{g}(\mathrm{x})$ describes the non-linear relationship between $S O C$ (state of charge) and open circuit voltage $\left(U_{\mathrm{OC}}\right)$. State vector $x$ is the output voltage of the RC circuits. Input $i$ stands for the current entering the battery, output $u$ stands for the voltage between the battery terminals. The developed battery model is shown in Fig. 4.

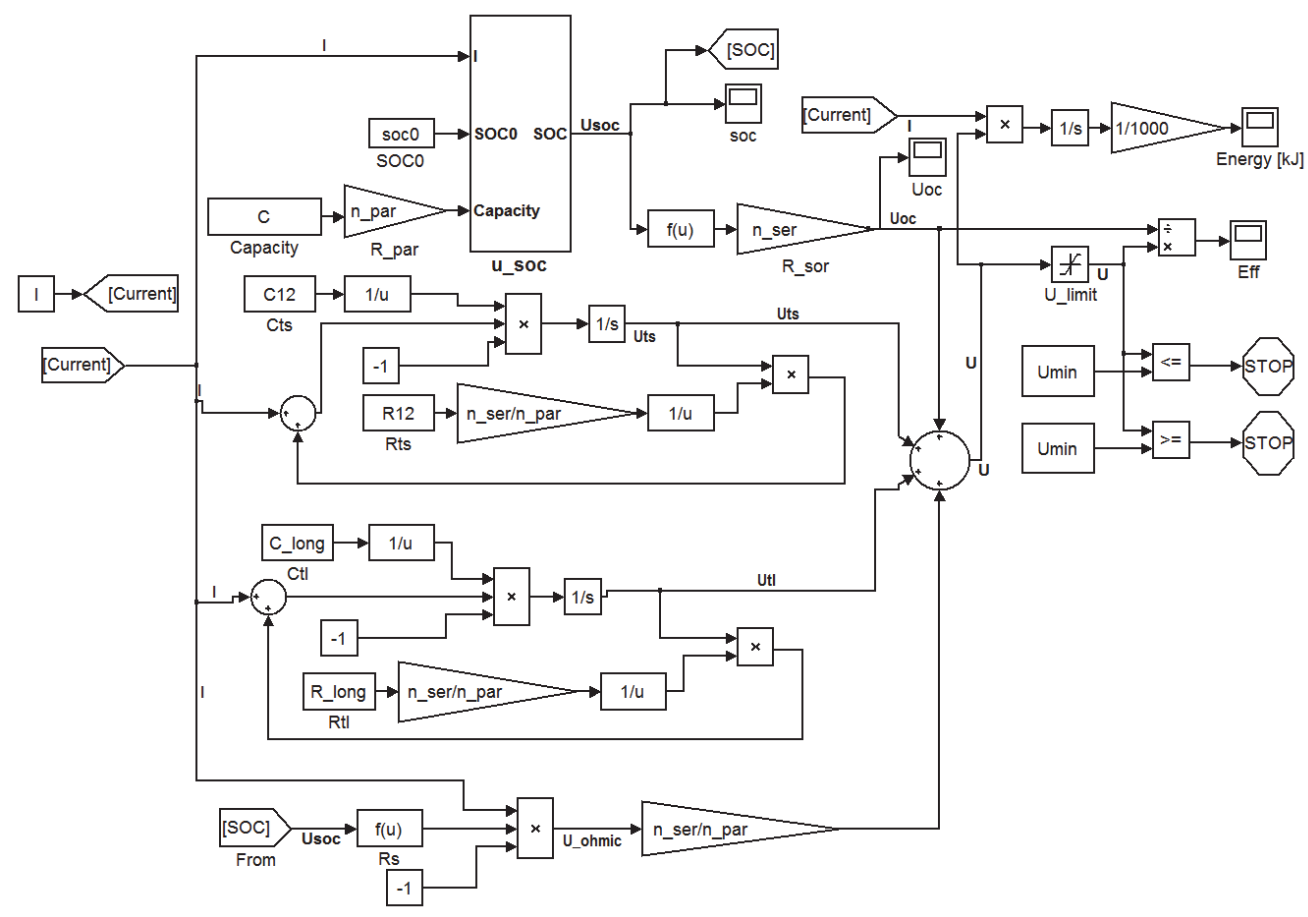

Figure 4. Battery model developed by ourselves

Since each parameter is the function of SOC, a sub-system for SOC modelling was created in order to simplify usability. The output value of the sub-system is a number between 0 and 1 . The change of parameters is given as a function of this value, with the help of a function block. The equation (3) [2] which describes how the SOC block works: 


$$
u_{\text {soc }}(\mathrm{t})=u_{\mathrm{soc}}(0)-\frac{1}{\mathrm{C}_{\mathrm{CAP}}} \int_{0}^{\mathrm{t}} i(\tau) \mathrm{d} \tau
$$

Block diagram of the SOC sub-system is shown in Figure 5:

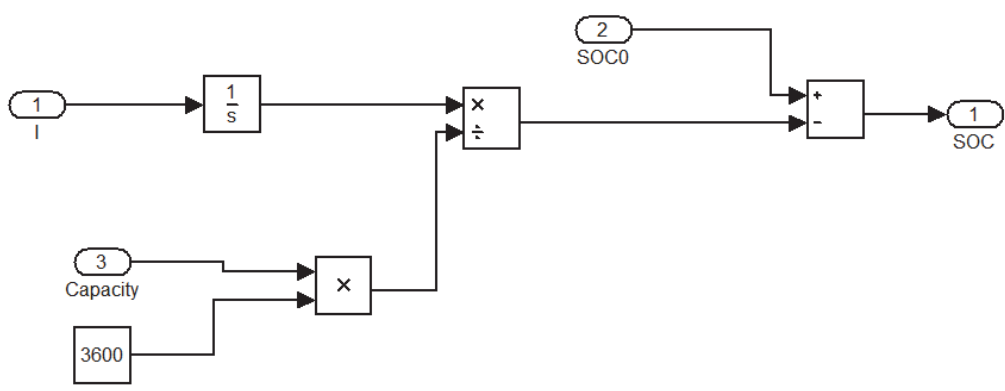

Figure 5. Modelling of SOC

The value of capacitance should be given in Ah and Simulink converts it into Coulomb according to formula (4):

$$
\mathrm{C}_{\mathrm{CAP}}[\mathrm{C}]=3600 \mathrm{C}_{\mathrm{CAP}}[\mathrm{Ah}]
$$

Parameters used by the model were taken in the first run from reference [1]. Later on, however, the parameters can be determined for the given battery type by means of own measurements.

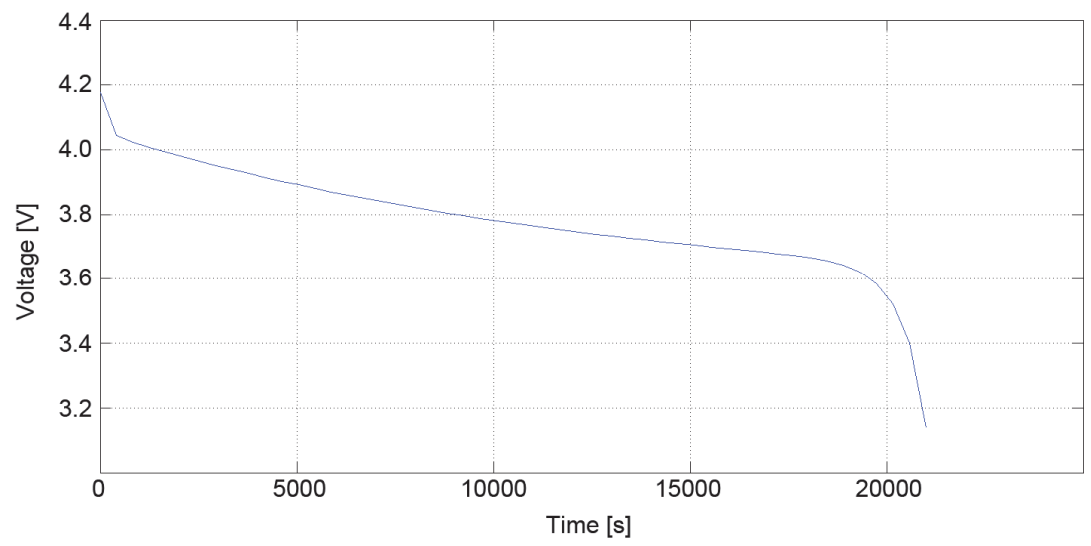

Figure 6. Voltage-time diagram of the initial battery model (discharging with $0.1 \mathrm{C}$ current) 


\subsection{Defining parameters with the help of measurements}

In the model, the relationship between Uoc-SOC and resistance-SOC were determined by means of curve fitting based on measurements.

There are several methods available for determining the $\mathrm{U}_{\mathrm{OC}}-\mathrm{SOC}$ diagram [4], [6]. Open circuit voltage-time diagram is shown in Fig. 7.

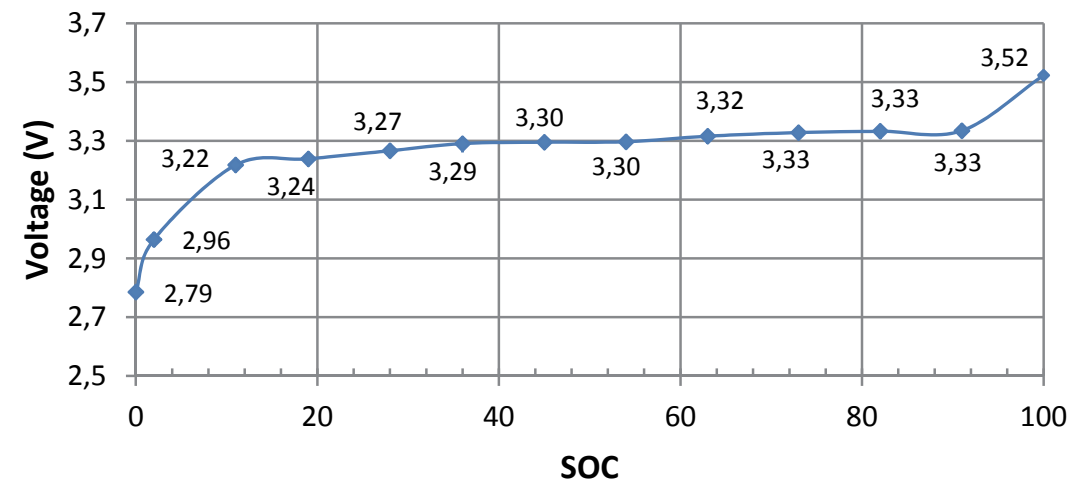

Figure 7. Open circuit voltage- SOC diagram of Thundersky 40 Ah battery (own measurement)

The curve was fitted by means of Matlab Curve Fitting Toolbox. The function used for approximation:

$$
\mathrm{V}_{\mathrm{OC}}(\mathrm{SOC})=\frac{\left(\mathrm{a}+\mathrm{b} \cdot \mathrm{SOC}+\mathrm{c} \cdot \mathrm{SOC}^{2}\right)}{\left(\mathrm{d}+\mathrm{e} \cdot \mathrm{SOC}+\mathrm{f} \cdot \mathrm{SOC}^{2}\right)}
$$

Approximation was done on one hand with basic Matlab Trust-region algorithm, on the other with Levenberg-Marquart algorithm. Fig. 8. shows that the approximation with Trust-region algorithm is not accurate enough, therefore, Levenberg-Marquart algorithm was selected for use.
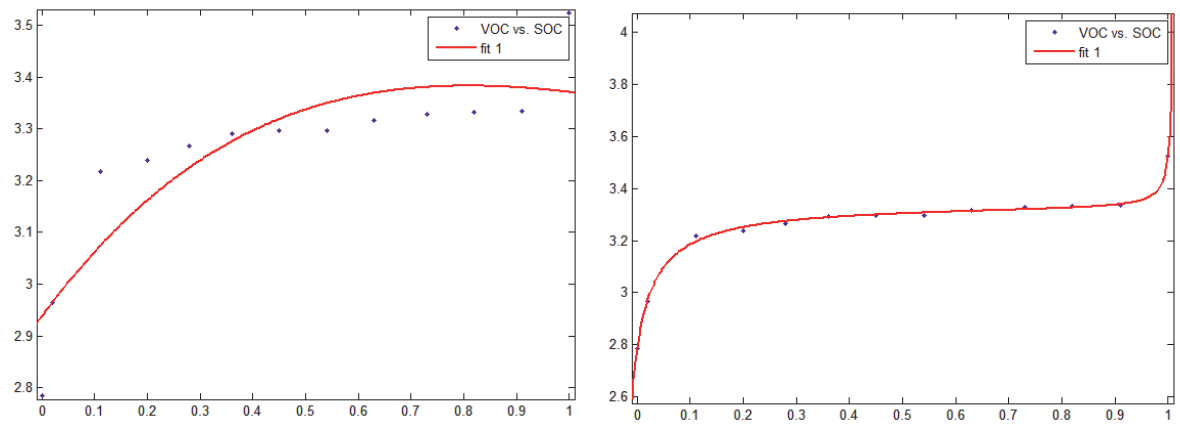

Figure 8. Fitted curve with Trust-region (to the left) and Levenberg-Marquardt (to the right) algorithm 
Formula (5) is applicable to any battery type, only the coefficients will change. Therefore, the variables for the simulations were given with the help of Matlab script.

Abu-Sharkh's and Doerffel's measurements were used as the bases for defining the rest of the parameter values [5]. The circuit diagram which we used for determining the parameters can be seen in Fig. 9.

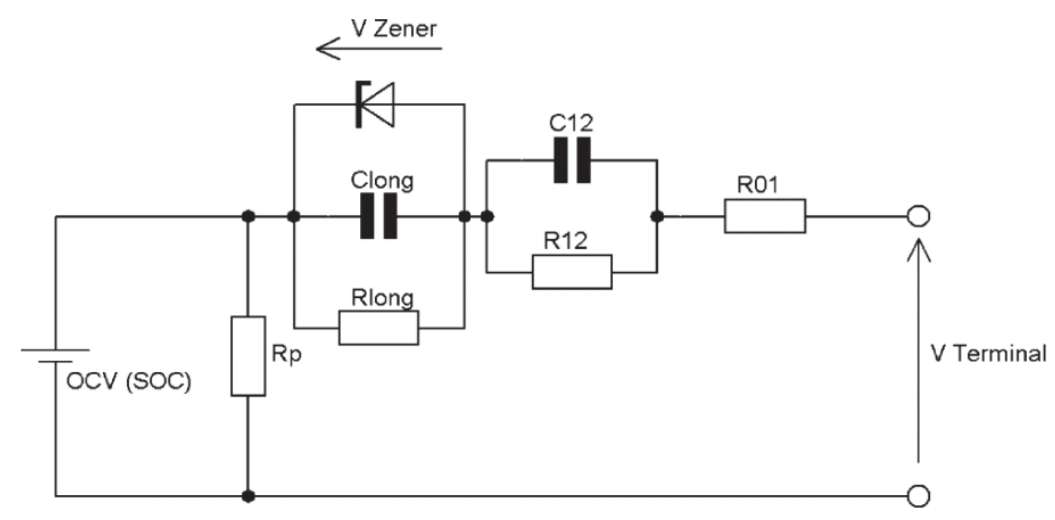

Figure 9 Circuit diagram of the battery model [5]

Symbols in Fig. 9:

- $\mathrm{OCV}\left(\mathrm{U}_{\mathrm{OC}}\right)$ : open circuit voltage,

- $\mathrm{R}_{\mathrm{p}}$ : self discharge resistance,

- $\mathrm{R}_{01}$ : ohmic resistance of the cell,

- $\mathrm{R}_{\text {long }}-\mathrm{C}_{\text {long }}$ circuit: describes the behaviour of the battery at low currents, like small standby load and equalising currents,

- $\mathrm{R}_{12}-\mathrm{C}_{12}$ circuit: determines the dynamic behaviour of the battery, for example at sudden high loads (when vehicle accelerates or brakes).

Among the parameters, the value of $\mathrm{U}_{\mathrm{OC}}, \mathrm{R}_{01}$ and $\mathrm{R}_{12}$ can be determined by this measurement.

Two charge-discharge cycles should be run during the test:

- The first cycle is needed for bringing the battery into the appropriate condition (conditioning cycle).

- While the second one is for determining the parameters of the battery.

There should be a one hour break between charge and discharge cycles in order to maintain the equilibrium potential. During the second cycle, one minute breaks should be held after each $2 \mathrm{mV}$ change. The process of the measurement is shown in Fig. 10. 


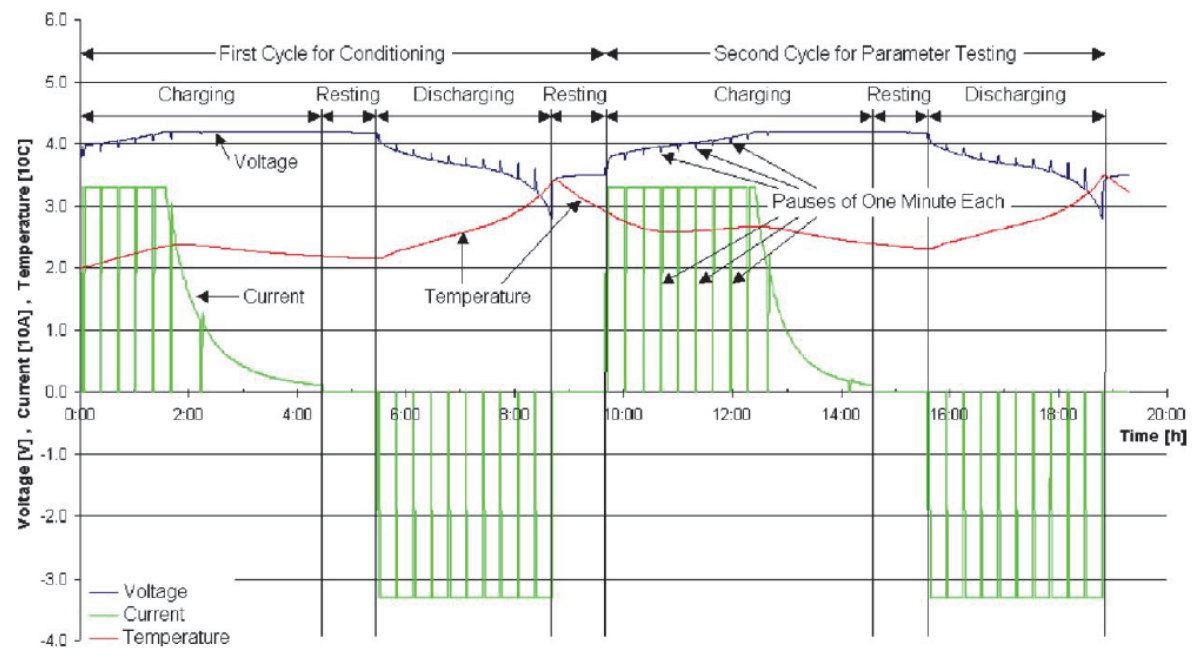

Figure 10. Characteristics of the measurement [5]

As a result of the one minute breaks, the voltage starts to recover. $R_{01}$ and $R_{12}$ values can be calculated from the recovery phenomenon. Voltage data needed for calculation are shown in Fig. 11.

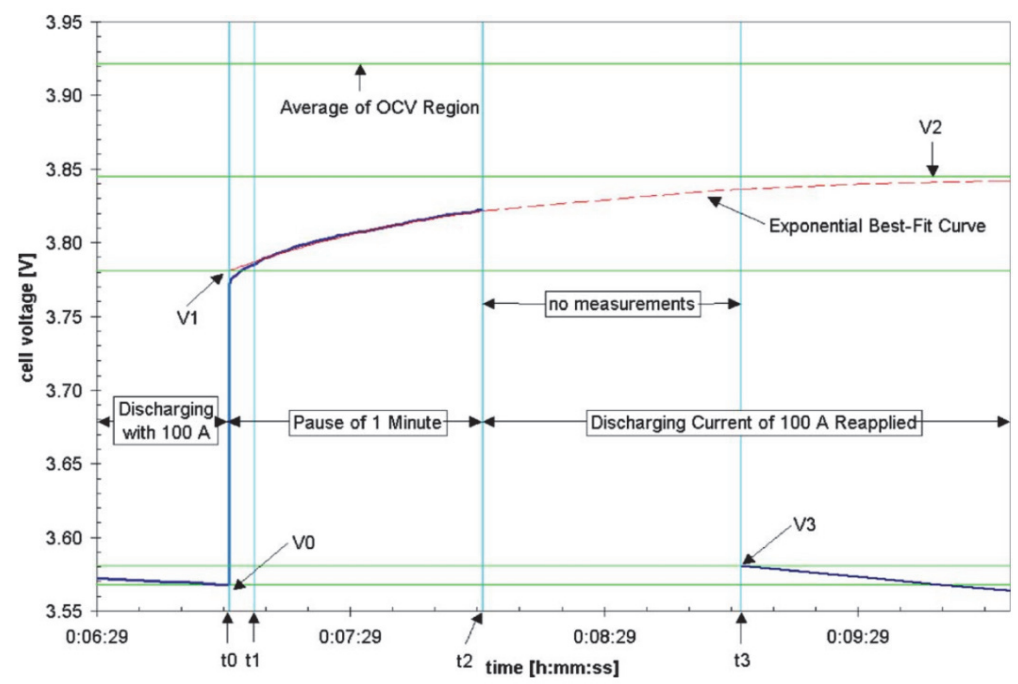

Figure 11.Voltage diagram to estimate the parameters [5] 


$$
\mathrm{R}_{01}=\frac{\mathrm{V}_{1}-\mathrm{V}_{0}}{|\mathrm{I}|}, \mathrm{R}_{12}=\frac{\mathrm{V}_{2}-\mathrm{V}_{1}}{|\mathrm{I}|}
$$

Internal resistance $\left(\mathrm{R}_{01}\right)$-SOC diagram measured by ourselves, shown in Fig. 12.

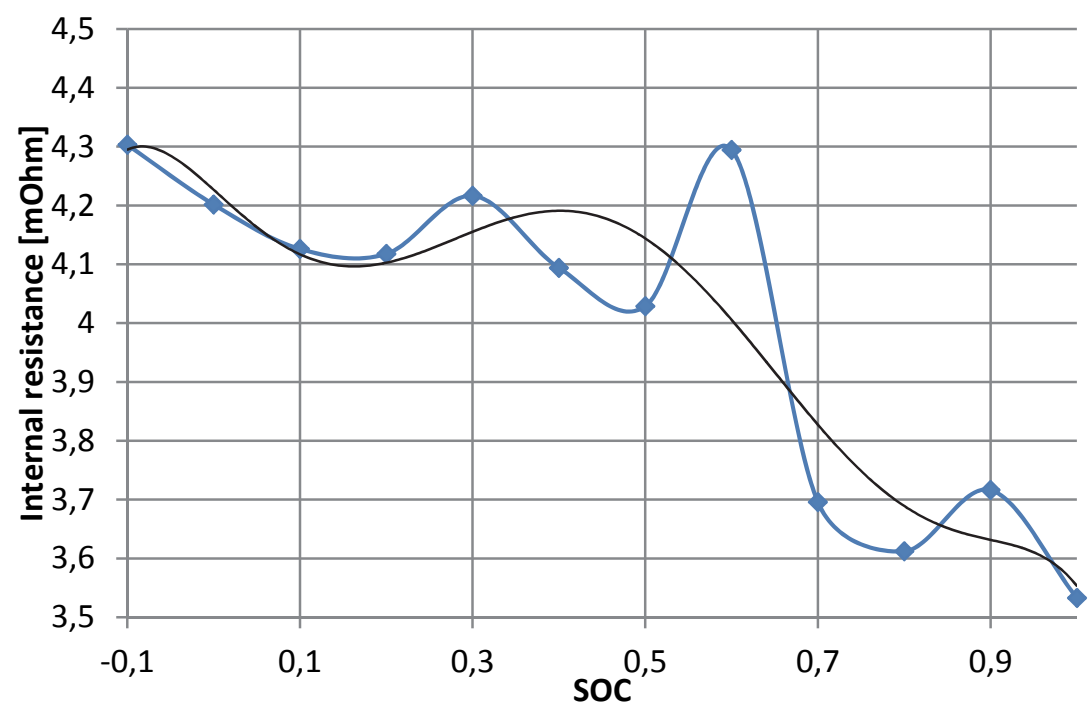

Figure 12. Internal resistance as a function of SOC (own measurement)

Similarly to the $\mathrm{U}_{\mathrm{OC}}$-SOC diagram, the function was determined by means of the Matlab Curve Fitting Toolbox. At first, it was approximated by a fifth degree polynomial, but, this caused large fluctuation of the output voltage. In case of third or second degree polynomials there is no fluctuation. The final $\mathrm{R}_{01}(\mathrm{SOC})$ function:

$$
R_{01}=-0,0011 \text { SOC }^{2}+0.0003 \text { SOC }+0,0042
$$

$R_{12}$ is given as a constant [2], its value: $R_{12}=3,87 \mathrm{~m} \Omega$. 


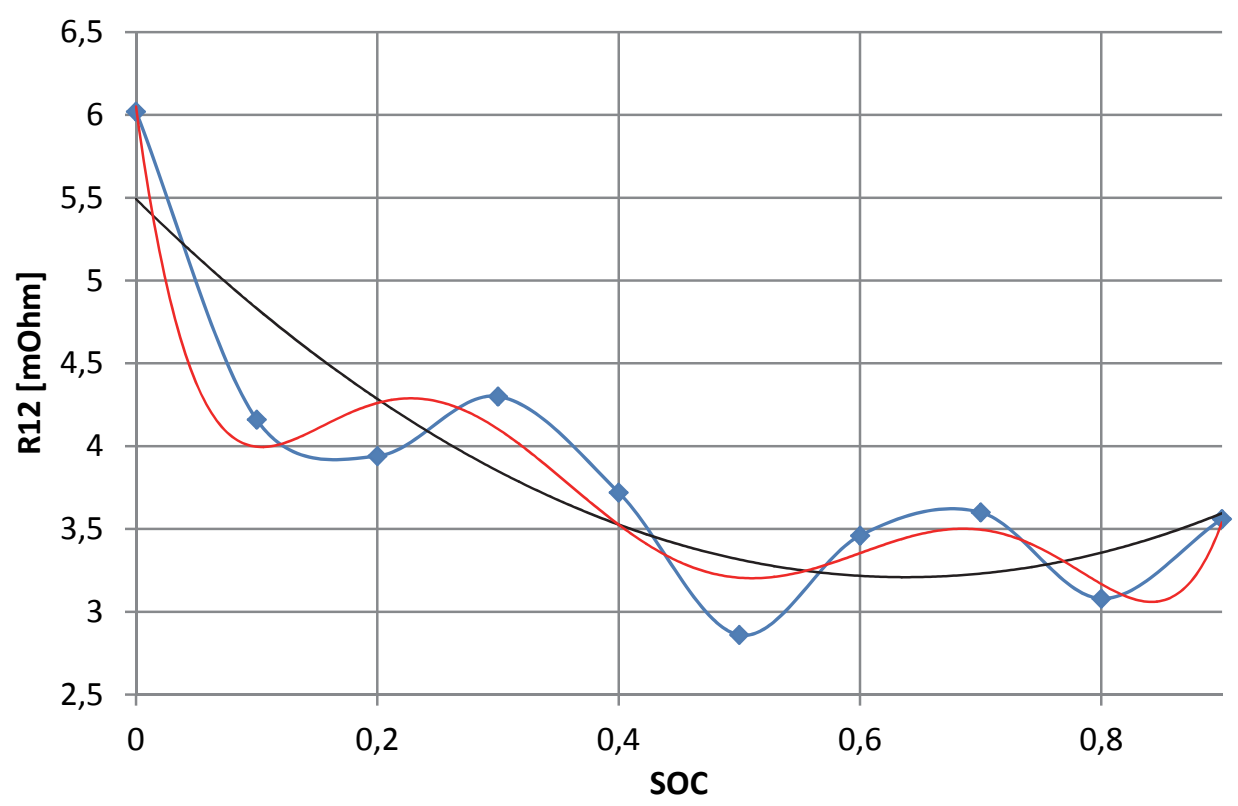

Figure 13. $R_{12}$ as a function of SOC (own measurement)

\subsection{Defining parameters in Simulink environment}

At first, the value of $R_{\text {long }}$ was set to $R_{\text {long }}=0,027909 \Omega$ based on reference [2]. Then the model was made more accurate with the help of measurement results. The voltage-time graph before and after parameter definition is shown in Fig. 14. 

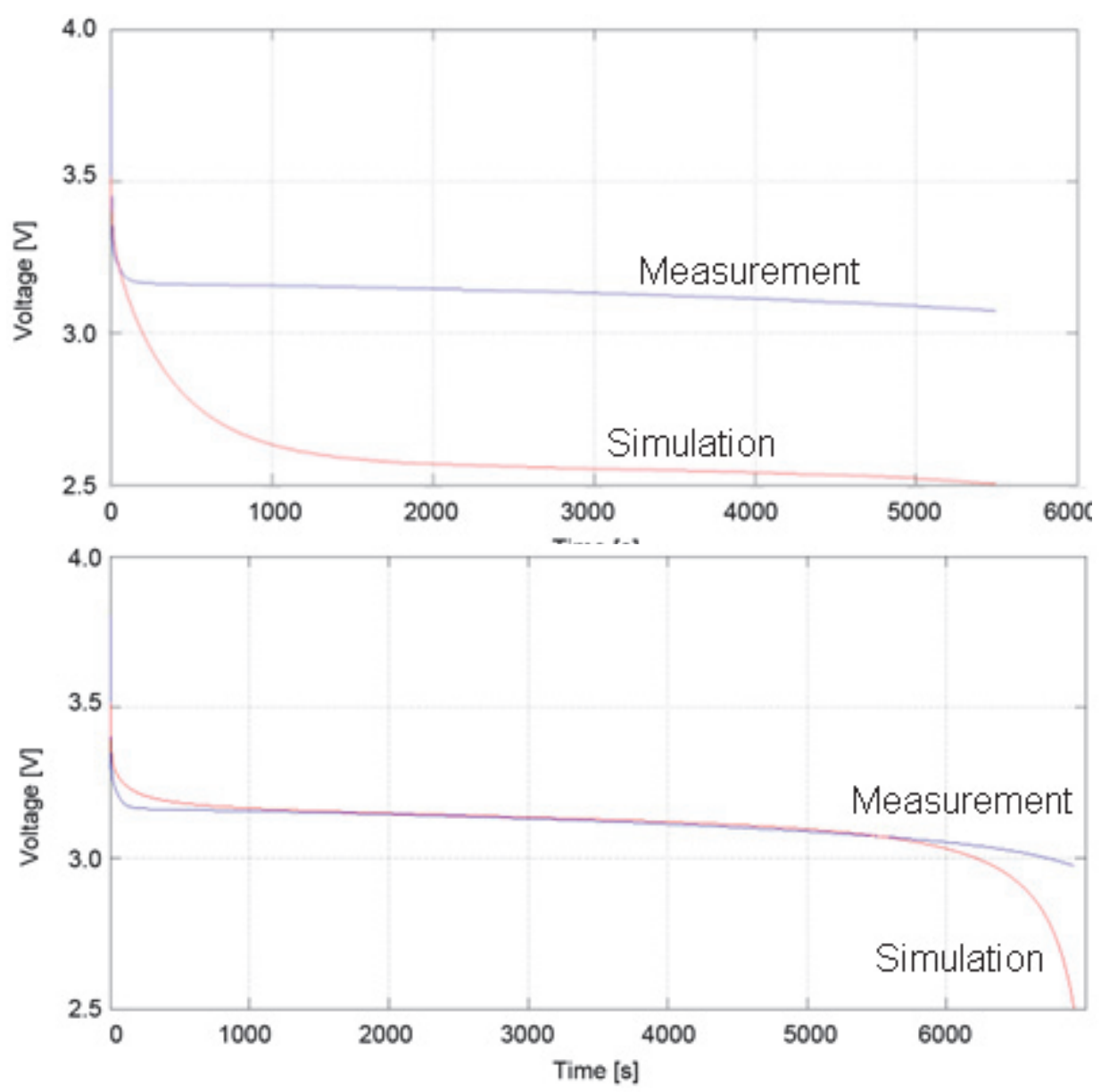

Figure 14. The voltage-time diagram before (to the top) and after (to the bottom) determining the value of $R_{\text {long }}$ (blue: measurement result, red: simulation result)

It can be seen in the diagram that the measured graph is well enough approximated by the simulated voltage values.

\subsection{Measurements necessary to further improve the battery model}

The following measurements are planned with the aim of battery model improvement and validation:

- current off-current on or HPPC (Hybrid Pulse Power Characterization) to determine Voc and the resistance values [8]

- Dynamic Discharge Performance Test to validate the model 


\section{Measurements already performed to validate the model}

\subsection{Battery measurement system}

The measurement system consists of separate charge and discharge modules. Modular scheme of the battery measuring system is shown in Figure 15.

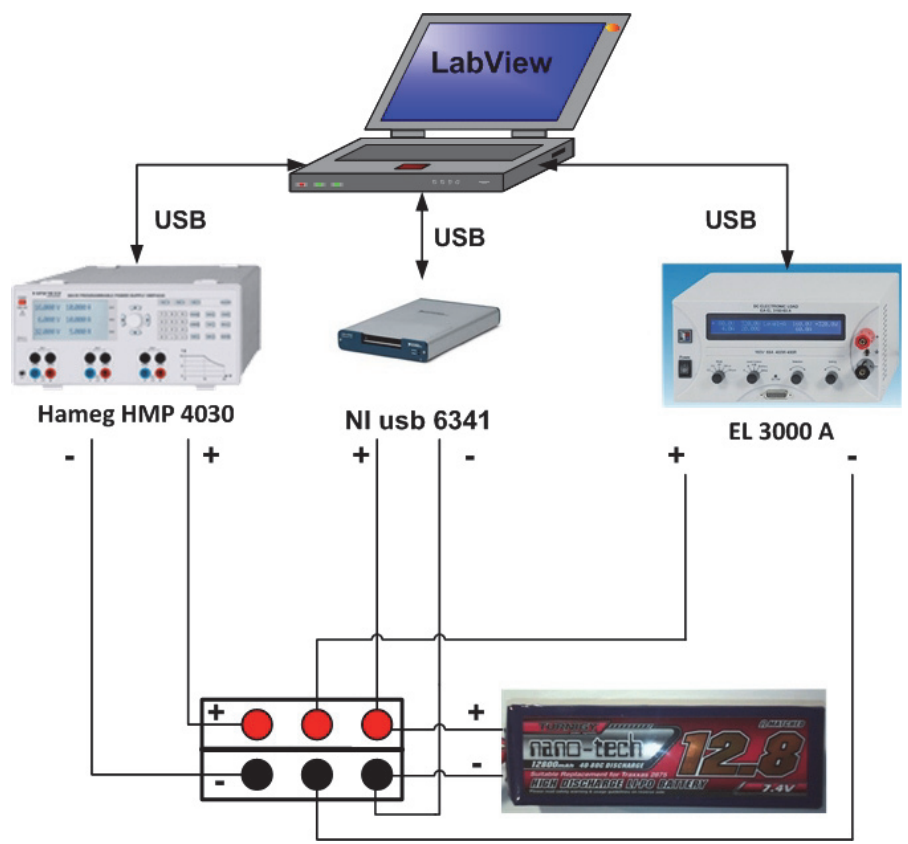

Figure 15. Modular scheme of the battery measuring system

Hameg power supply unit (HMP 4030) was used for the purpose of charging. The unit is controlled via Labview software. Communication between the unit and the computer is done via USB. The program developed in Labview is shown in Fig. 16.
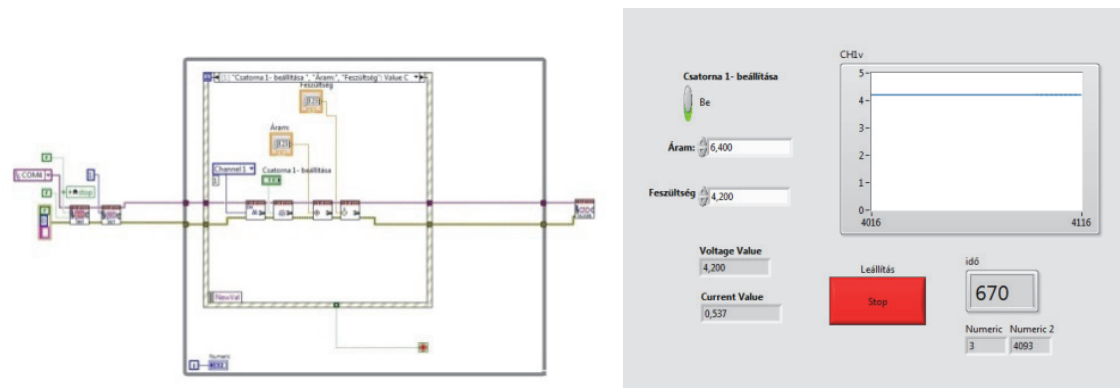

Figure 16. Labview charging program 
During charging, it is possible to adjust the voltage and current of the charger with the help of the program. $100 \%$ charge of the cell was indicated by its voltage reaching 4.2 V.

Constant current/constant voltage strategy was used for charging (cc/cv: cc - constant current, cv - constant voltage). The battery was charged with constant current in the first phase of the charging process. As soon as SOC approaches $100 \%$, the charge current is decreased by the charger automatically and then switches to constant voltage keeping. Charging ends when charge current decreases below 3\% of the preset charge current. In this case, with preset $6.4 \mathrm{~A}$ it means $0.192 \mathrm{~A}$.

Dummy load EL 3000 A was used for discharging.

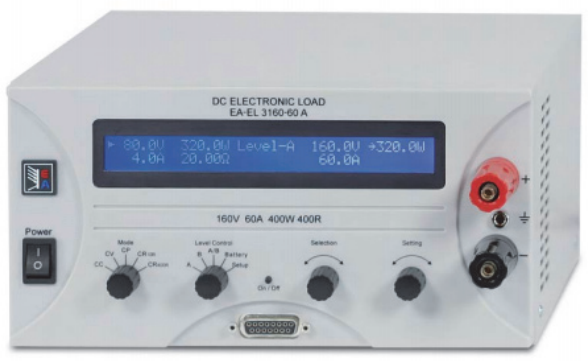

Figure 17. Dummy load EL 3000 A

The dummy load was controlled by means of the original software via USB port of the computer.

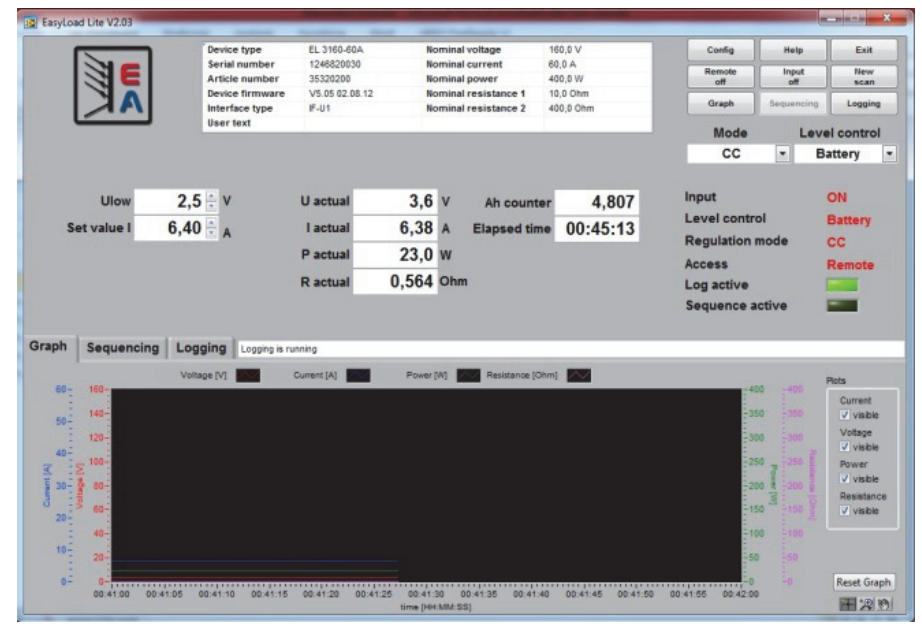

Figure 18. Control software EL 3000 


\subsection{Testing of the Turnigy nano-tech $12800 \mathrm{mAh}$ battery}

The Turnigy nano-tech $12800 \mathrm{mAh}$ battery was used as testing medium because the very same battery was applied in the new vehicle of the SZENERGY Team. The whole package is built up of two cells connected in line and two parallel.

It was decided that the maximum voltage should be $4.2 \mathrm{~V}$, and the minimum should be $2.5 \mathrm{~V}$. The test was performed on one cell and also on the whole battery package. The cell or the package was charged at first to $100 \%$ SOC, than after one hour pause discharge started. Voltage-time and current-time diagrams are shown in Fig. 20-23.

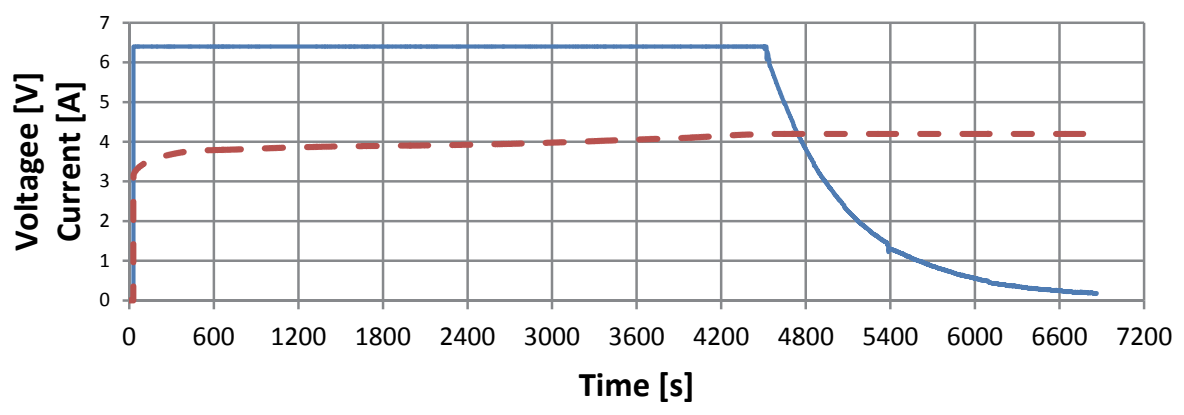

Figure 19. Voltage-time (dashed line) and current-time (solid line) diagrams when charging one cell

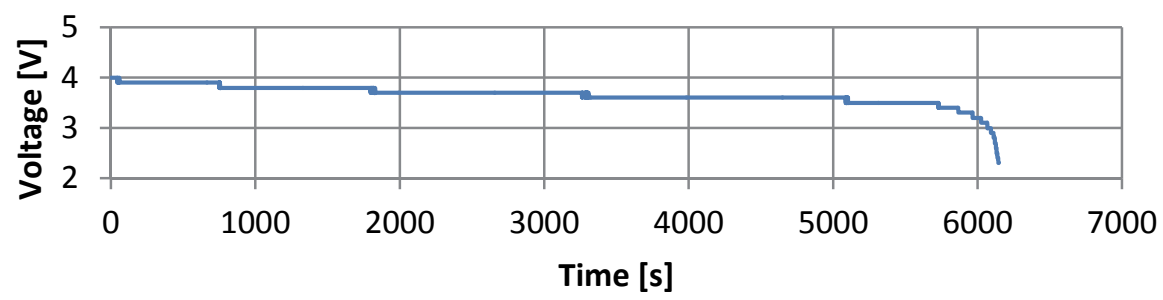

Figure 20. Voltage-time diagram when discharging one cell 


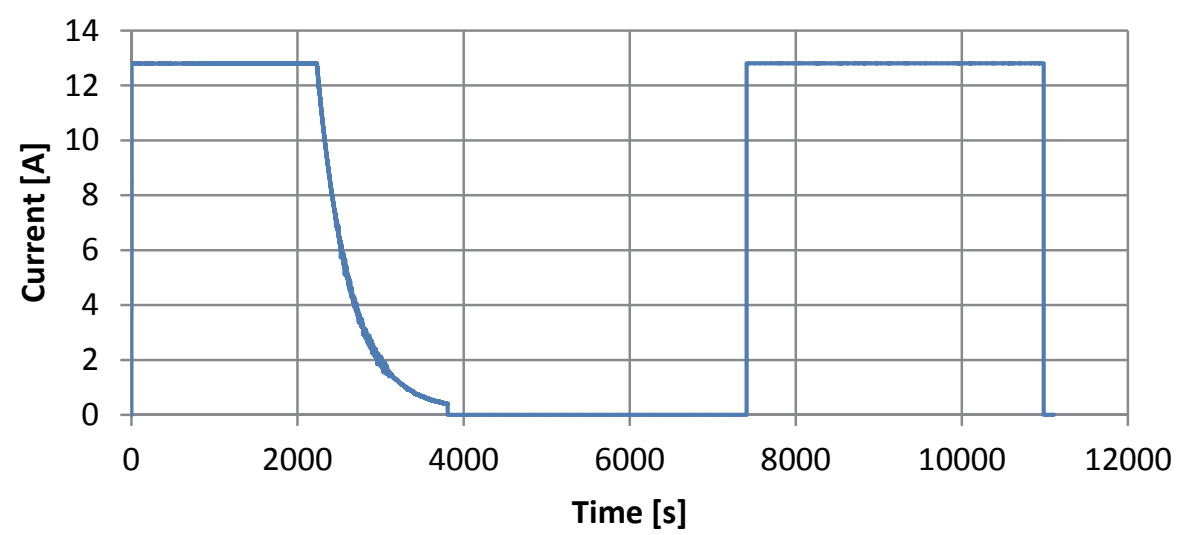

Figure 21. Current-time diagram when charging and discharging one battery package

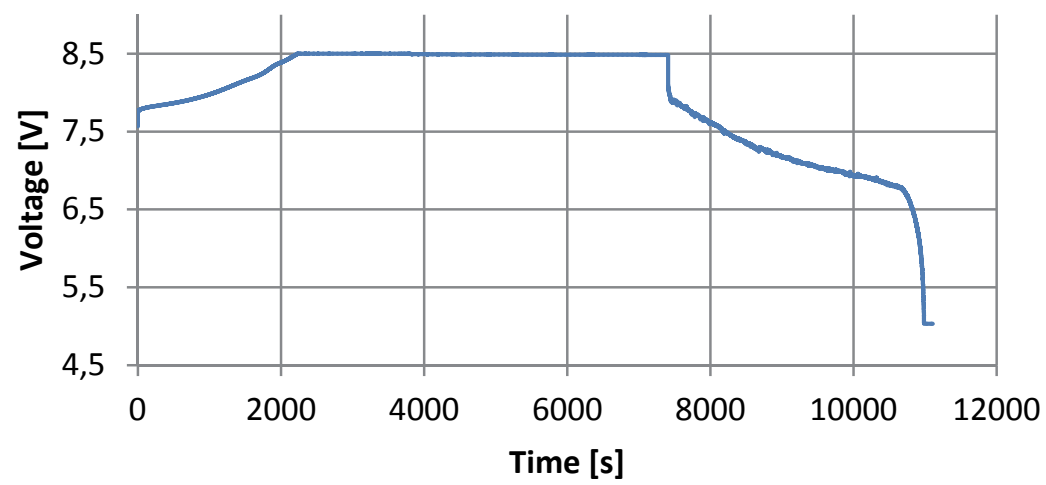

Figure 22. Voltage-time diagram of the package (whole cycle)

\section{Summary}

The initial steps of building the simulation model have been taken. Currently, the preparation of the measurements is in progress in order to validate the model. It is planned to demonstrate by means of simulating sensor malfunctions how the quality of the sensors influence the diagnostic models, in this manner, the value in use of the vehicle. The above connection can easily be understood when one thinks of the fact that the current range of the vehicle is determined by the state of charge of its battery.

\section{Acknowledgement}

TÁMOP-4.2.4.A/2-11/1-2012-0001 identification number of the National Excellence Program - was the establishment and operation system for domestic students, researchers and staff support as a priority project by the convergence program. The project is funded by the EU, the European Social Fund co-funded. 


\section{References}

[1] Chen, M., Rincón-Mora, G.A: Accurate Electrical Battery Model Capable of Predicting Runtime and I-V performance, IEEE Transactions on energy conversion, vol. 21, no. 2, pp 504-511, 2006

[2] Knauff, M., McLaughlin, J., Dafis, C., Niebur, D., Singh, P., Kwatny, H., Nwankpa, C.: Simulink Model of a Lithium-Ion Battery for the Hybrid Power System Testbed, IEEE Electric Ship Technologies Symposium - ESTS, pp. 421427, Arlington, 2007

[3] Hajdu F., Lakatos I. Phd, Körös P.: Lithium battery modelling in Simulink environment (in Hungarian), IFFK, pp.132-140., Budapest, 2013

[4] Rahimi-Eichi, H., Chow, M.Y.: Adaptive Parameter Identification and State-ofCharge Estimation of Lithium-Ion Batteries, 38th Annual Conference of the IEEE Industrial Electronics Society, Montreal, 2012

[5] Abu-Sharkh, S., Doerffel, D.: Rapid test and non-linear model characterisation of solid-state lithium-ion batteries, Journal of Power Sources vol. 130, no. 1-2., pp.266-274, 2004

[6] Wu, T., Liu, L., Xiao, Q.,Cao, Q., Wang, X.: Research on SOC Estimation Based on Second-order RC Model, Journal of Asian Electric Vehicles,Vol. 8, No. 2, pp.1419-1423., 2010

[7] Daowd, M., Omar, N., Verbrugge, B., Van Den Bossche, P., Van Mierlo, J.: Battery Models Parameter Estimation based on Matlab/Simulink, The 25th World Battery, Hybrid and Fuel Cell Electric Vehicle Symposium \& Exhibition, Shenzhen, 2010

[8] Omar, N., Daowd, M., Hegazy, O., Mulder, G., Timmermans, J.M., Coosemans, T., Van den Bossche, P., Van Mierlo, J.: Standardization Work for BEV and HEV Applications: Critical Appraisal of Recent Traction Battery Documents, Energies (19961073) Vol. 5. No. 1, pp. 138-156, 2012 